\title{
A CPR MODEL FOR MODIFIED MUSIC STANDARDS IN PROFESSIONAL MUSIC TRAINING: THE CASE OF TUT
}

\author{
Hua Hui Tseng \\ Music Department, Tainan University of Technology (Taiwan)
}

\begin{abstract}
The purpose of this paper is to use the National Association for Music Education's three artistic processes of creating, performing, and responding (CPR) guidelines for music teachers, music supervisors and administrators, and school boards, legislators, and other decision-makers to analyze and explore evaluation measures and the process of giving students tools in instructional programs that would lead them to become successful and competitive learners. Consideration is given to the areas and practices of the guidelines in the process of evaluating student learning across a range of standards representative of the quality of learning outcomes and balanced music curriculum that includes not only responding to music but also creating and performing music. The case of the Music Department in the Tainan University of Technology (TUT), Taiwan, is used to gain insight into some of the implications of student results. The findings demonstrate that a true assessment of music performance in authentic contexts is realized by raising the quality of practice, defined as meeting learning objectives in performance, that conform to the criteria of academic and performance requirements.
\end{abstract}

Keywords: Assessment, measurement, standards.

\section{Introduction}

Assessment in higher education has been under scrutiny since 1990 (Rawlusyk, 2018, p. 34), and music assessment is included is the areas "identified by those in the measurement community as prime examples of unreliable measurement" (Parkes, 2012, p. 98). Researchers from the National Association for Music Education, Centre for Educational Research and Innovation (CERI), American Educational Research Association (AERA), American Psychological Association (APA), and National Council on Measurement in Education (NCME) conducted a study indicating that the education assessment process is designed to self-examine program performance and quality by providing feedback to participants and stakeholders and those "who develop tests, who use tests, and who take tests" (Reynolds, Livingston, \& Willson, 2009, p. 15). Professional educational assessment provides essential "information that is used for making decisions about students, curricula and programs, and educational policy" (Mazur \& Łaguna, 2017, p. 119) and provides information to assist policy makers "become competent in selecting and using assessments" (p. 115). Assessment helps improve the value of the decisions made and outcomes produced.

Continuously assessing the assessment process also provides an opportunity for commercial test publishers, professionals, and researchers to exchange views on "guidelines for the ethical and responsible use of tests" (Reynolds et al., 2006, p. 14). Lyotard (1983/1988, p. 13), Reynolds et al. (2006, p. 14), Bradley (2011, p. 79), and Richerme (2016, p. 284) noted the process of assessing assessment draws on information gleaned from the revised 2014 National Core Music Standards, like the 1994 predecessors, namely, Standards for Educational and Psychological Testing (AERA , 1999), accredited by the American National Standards Institute (ANSI); The Student Evaluation Standards (Joint Committee on Standards for Educational Evaluation [JCSEE], 2003); Code of Professional Responsibilities in Educational Measurement (NCME, 1995); and Code of Fair Testing Practices in Education (Joint Committee on Testing Practices [JCTP], 1998), among others. While assessments are focused primarily on the people involved, the whole assessment process is used to examine whether the participants and instruments have achieved their stated objectives (Richerme, 2016). 


\section{Purpose of study}

The purpose of this paper is to provide a review of noteworthy developments at the Tainan University of Technology (TUT), Taiwan, Music Department's seven-year program from high school directly to a bachelor's degree in vocational education. A performance assessment process at the TUT has been selected to discuss criteria and guidelines for measuring the effectiveness of both student assessment and the ongoing process of program evaluation. Selected areas for consideration are the following:

- The selection and/or development of instruments;

- Alignment to existing programs;

- Student rights and responsibilities;

- Prevention of bias;

- Instructor and administrator responsibilities;

- Student achievement;

- Accommodations;

- Issues in developing, selecting, scoring, and interpreting students' results.

In this paper, the above processes are explored with reference to the TUT's various goals and strengths, and the opportunity is used to make recommendations for improvement. Alignment with these processes could offer important criteria for defining and communicating measures for evaluating questions and objectives. Ensuring schools have access to recent and multiple forms of assessment has contributed to "emphasizing the intra-active nature of measurement and empower[ing] themselves to critique and reimagine existing measurement apparatuses and their measurement and assessment practices" (Richerme, 2016, p. 174). Additional creative measures are required for schools to rise to the challenge of "assessment criteria, such as the overall impression of the performance, technical ability, expressive components, and the basic parameters of the quality of the performance" (Mazur \& Łaguna, 2017, p. 115). Equally important is ensuring students are competent in creating, performing, and responding to enhance results and conclusions.

\section{Strengths of seven-year program at TUT}

As Bergee (2003) noted, "Assessment of music performance in authentic contexts remains an under-investigated area of research" (p. 137). Bergee also developed an assessment process to evaluate performance aspects using criteria-specific rating scales, which "are more comprehensive, encouraging attention to all aspects of the performance and providing balanced feedback to performers" (p. 147).

Performance assessment has also been seen as a meaningful task for creating the critical link between teaching and learning in more applied music settings (Parkes, 2010). As Parkes (2010) noted, "Performance assessments must have transparent criteria, be fair, be generalizable and transferable, have cognitive complexity and content quality, and be comprehensive" (p. 101). At the TUT's Music Department, performance assessments are seen to have their own set of strengths, and Parkes (2010, p. 249) cites several researchers' summaries as follows:

Assessment tasks clarify the meaning of complex learning targets. Assessment tasks allow students to allocate the correct amount of effort to the aspects of the course (Gibbs \& Simpson, 2004-2005, p. 12-14), engage students in productive learning activity, and ensure feedback is given on the tasks often and in suitable detail (p. 14-17). Assessments also allow students to focus on the feedback appropriately in relation to what they think they are supposed to be doing (p. 18-21), receive and attend to feedback, and that act on the feedback (p. 23-24).

Performance tasks require integration of knowledge, skills, and abilities. Performance assessments require students to demonstrate their learning outcomes through complex performance tasks. For example, the TUT's music appreciation competency evaluation assesses inspiration, rhythm, melody, harmony, and tone, and students are asked to demonstrate their music appreciation ability by showing measurable knowledge about what to listen for in music.

Performance assessments may be linked more closely with teaching activities. Performance assessments include solo and ensemble performances, using a holistic rubric for tutors to use in grading written work. However, reports from tutors revealed they simply 'adapted' the descriptors to their own existing grading processes. Student responses were also mixed with comments indicating they preferred more personalized comments added to the rubric as part of the feedback (Parkes, 2010, p. 99).

Assessments do provide students opportunities to intra-act with their musical surroundings. Reynolds et al. (2009) asserted, "Performance assessments require test takers to complete a process or produce a product in a context that closely resembles real-life situations" (p. 23). At the TUT, students in the Music Department's seven-year program are required to take both academic credits and performing 
credits. The questions raised is how can staff as the TUT make sure learning outcomes are effective? Some types of evaluation used are derived from Simon (2014) such as, Needs Assessment (paper-pencil tests), Formative Evaluation (expert consultation, vertically aligned), Summative Evaluation (feedback from the jury evaluating the performance, horizontally aligned), "norm-referencing" (relative standards), and "criterion-referencing" (absolute standards) (p. 86). A score of 60 is required to pass.

Assessment tasks let teachers assess the processes students use as well as the products they produce. At the TUT, for example, solo piano performance assessments are "focus[ed] on key points of instruction" (Common Arts Assessment Initiative, 2014, p. 1) and include such areas as "Interpretation/Musical Effect, Rhythm/Tempo, and Technique" (Bergee, 2003, p. 143).

\section{Conclusion}

As Parkes (2010) noted, the features of assessment as explained by Shepard (2000) can be seen in the higher education literature across several countries, and more importantly, the research of music performance literature. The increasing demand for "standard-setting process primarily involves consideration of qualitative, evaluative criteria, only then to be followed with the support of the quantitative measurement data" (Wesolowski et al., 2018, p. 226), and this has heightened the need for music performance evaluation. In this paper, an attempt was made to explain the performance assessment process at the TUT to show what reliability means in a current music education context.

\section{References}

American Educational Research Association, American Psychological Association, \& National Council on Measurement in Education. (1999). Standards for educational and psychological testing. Washington, DC: American Educational Research Association.

Bergee, M. J. (2003). Faculty interjudge reliability of music performance evaluation. Journal of Research in Music Education, 51(2), 137-148.

Bradley, D. (2011). In the space between the rock and the hard place: State teacher certification guidelines and music education for social justice. Journal of Aesthetic Education, 45(4), 79-96. doi:10.5406/jaesteduc.45.4.0079

Common Arts Assessment Initiative. (2014). Retrieved from http://www.nafme.org/my-classroom/ standards/mcas-information-on-taking-part-in-the-field-testing/Common Core State Standards

Danielson, C., \& McGreal, T. L. (2000). Teacher evaluation to enhance professional practice. Alexandria, VA: Association for Supervision and Curriculum Development.

edTPA. (2015). Educative assessment \& meaningful support: 2014 edTPA administrative report. Amherst, MA: Author.

Gibbs, G., \& Simpson, C. (2004-2005). Conditions under which assessment supports students' learning. Learning and Teaching in Higher Education, 1(1), 3-30. doi:10.1007/978-3-8348-9837-1

Joint Committee on Standards for Educational Evaluation. (2003). The student evaluation standards. Thousand Oaks, CA: Corwin Press.

Joint Committee on Testing Practices. (1998). Code of fair testing practices in education. Washington, DC: American Psychological Association.

Lyotard, J. (1988). The differend: Phrases in dispute (G. Van Den Abbeele, Trans.). Minneapolis, MN: University of Minnesota Press. (Original work published 1983)

Marzano, R. J. (2007). The art and science of teaching: A comprehensive framework for effective instruction. Alexandria, VA: Association for Supervision and Curriculum Development.

Mazur, Z., \& Laguna, M. (2017). Assessment of instrumental music performance: Definitions, criteria, measurement. Edukacja. An interdisciplinary approach, 115-128. doi:10.24131/3724.170508

National Council on Measurement in Education. (1995). Code of professional responsibilities in educational measurement. Washington, DC: Author.

Nitko, A. J. (2004). Educational assessment of students (4th ed.). Upper Saddle River, New Jersey: Pearson Education.

Parkes, K. A. (2012). Performance assessment: Lessons from performers. International Journal of Teaching and Learning in Higher Education, 22(1), 98-106.

Reynolds, C. R., Livingston, R. B., \& Willson, V. (2009). Measurement and assessment in education (2nd ed.). Boston, MA: Pearson Education.

Rawlusyk, P. E. (2018). Assessment in Higher Education and Student Learning. Journal of Instructional Pedagogies, 21, p.34. 
Richerme, L. K. (2016). Measuring music education: A philosophical investigation of the model cornerstone assessments. Journal of Research in Music Education, 64(3), 274-293. doi: $10.1177 / 0022429416659250$

Serenko, A. (2011). Student satisfaction with Canadian music programmes: The application of the American customer satisfaction model in higher education. Assessment \& Evaluation in Higher Education, 36(3), 281-299. doi:10.1080/02602930903337612

Simon, S. H. (2014). Using longitudinal scales assessment for instrumental music students. Music Educators Journal, 101(1), 86-92. doi:10.1177/0027432114539704

Wesolowski, B. C., Athanas, M. I., \& Burton, J. S. (2018). Judgmental standard setting: The development of objective content and performance standards for secondary-level solo instrumental music assessment. Journal of Research in Music Education, 66(2) 224-245. doi:10.1177/0022429418765482 